\title{
Postpartum Thyroiditis
}

National Cancer Institute

\section{Source}

National Cancer Institute. Postpartum Thyroiditis. NCI Thesaurus. Code C114389.

Inflammatory disorder of thyroid gland that occurs postpartum due to any partum problem. 